\title{
Synthesis and Characterisation of Calcium Carbonate Aragonite Nanocrystals from Cockle Shell Powder (Anadara granosa)
}

\author{
Abdullahi Shafiu Kamba, ${ }^{1}$ Maznah Ismail, ${ }^{1}$ \\ Tengku Azmi Tengku Ibrahim, ${ }^{2}$ and Zuki Abu Bakar Zakaria ${ }^{1}$ \\ ${ }^{1}$ Laboratory of Molecular Biomedicine, Institute of Bioscience, Universiti Putra Malaysia, 43400 Serdang, Malaysia \\ ${ }^{2}$ Faculty of Veterinary Medicine, Universiti Putra Malaysia, 43400 Serdang, Malaysia \\ Correspondence should be addressed to Zuki Abu Bakar Zakaria; mdzukiabubakar@gmail.com
}

Received 24 November 2012; Accepted 24 March 2013

Academic Editor: Yun Zhao

Copyright (C) 2013 Abdullahi Shafiu Kamba et al. This is an open access article distributed under the Creative Commons Attribution License, which permits unrestricted use, distribution, and reproduction in any medium, provided the original work is properly cited.

The synthesis of pure calcium carbonate nanocrystals using a high pressure homogeniser (HPH) via a microemulsion system produced uniform nanosized particles, which were characterised using transmission electron microscopy (TEM), fieldemission scanning electron microscopy (FESEM), X-ray diffraction (XRD), Fourier transform infrared spectroscopy (FTIR), and thermogravimetric analysis (TGA). The identified particles were aragonite polymorphs with a rod shape and were approximately $50 \mathrm{~nm}$ in size. The aragonite polymorph of calcium carbonate was prepared from biogenic materials, cockle shells, and exhibited unique characteristics (i.e., a higher density than that of calcite), which makes it biocompatible and potentially suitable for applications in the medical, pharmaceutical, cosmetic, and paint industries. The methods adopted and the nonionic surfactant used in the synthesis of calcium carbonate nanocrystalline aragonite polymorphs were environmentally friendly and can be scaled up for industrial production. The sources are naturally available materials that are by-products of the seafood industry, which offers an opportunity for exploitation in numerous industrial applications.

\section{Introduction}

Calcium carbonate nanoparticles are abundant inorganic biomaterials with different morphological structures that have attracted the interest of researchers in different fields. This interest is due to the wider application of these nanoparticles in many industries, such as the paint, rubber, and plastics industries. With the present focus of interest in nanotechnology, calcium carbonate nanoparticles have been observed to be biocompatible for use in medicine, pharmaceutical industries, and drug delivery systems $[1,2]$. The most important aspect with respect to the synthesis of nanoparticles is control of the particle size, polymorphism, and morphology of the desired material. Control of this parameter has led to the development of new materials with unique properties that differ from those in the bulk material [3]. Many studies have been conducted to mimic nature in the synthesis of nanomaterial with the aim of analysing the biogenic materials and identifying how nature controls the morphology, size, and polymorphism in organisms.

Biomineralization is the process by which a living organism secretes inorganic material in the form of a skeleton, a shell, teeth, or bone [1]. These processes are natural, are often performed with a high level of spatial control, and usually occur in a confined reaction environment. The organic matter or biopolymers observed in the hard tissue, such as the bones, teeth, and shells of living organisms, have the unique capacity to control the morphology, crystal size, polymorphism, and structure of the inorganic material. These biopolymers are usually soluble and are referred to as a functional matrix [13]. Biomaterials are highly optimised materials with remarkable properties, and they serve as natural archetypes for future materials [1]. These unusual properties have recently attracted the attention of numerous researchers, including both materials chemists and researchers in the medical and pharmaceutical sciences because of the biogenic origin and 
potential biocompatibilities of these materials [3]. Biomaterials with an optimised structure exhibit better performance, durability, and appearance, which offers valuable opportunities for the development of new techniques for the synthesis and control of nanostructures materials with potential applications in pharmaceuticals, cosmetics, drug delivery, medicine, microelectronics, and energy technology [3].

Biological systems are capable of producing inorganic materials such as calcium carbonate with different structures, morphologies, and polymorphs. Such biological systems are observed in numerous marine organisms such as oyster shells, coral, ivory sea urchin, and mollusc shell bivalve nacre, whereby the main components of the shells are calcium carbonate and other organic components, such as anionic protein and glycoprotein [4].

Currently, research with respect to cockle shells, in which the primary component is approximately $98-99 \%$ calcium carbonate, is in its infancy $[5,6]$. Calcium carbonate has three anhydrous crystalline phases: calcite, which is thermodynamically stable under ambient conditions; aragonite, which is a high-pressure polymorph that is less stable than calcite; and vaterite, which is the least stable among the three polymorphs and has the ability to transform into one of the other two polymorphs [7]. Different techniques for the preparation of calcium carbonate nanoparticles have been reported, including the precipitation of homogeneous solutions [8], waterin-oil-in-water emulsions [9], mechanochemical and sonochemical syntheses [10] and water-in-oil (W/O) microemulsions [11]. Other preparation methods include the highpressure homogeniser (HPH) technique and high-gravity precipitation. For precipitation methods, two different routes have been reported with the only difference being the chemicals used. The first method is based on the carbonation process, whereby carbon dioxide gas is bubbled through aqueous slurry of calcium hydroxide at specific temperature in present of organic additive such as surfactant thereby inducing precipitation of calcium carbonate. The second method is known as double decomposition and involves the combination of salt of calcium ions with salt of carbonate ions, such as the reaction of calcium chloride or calcium nitrate with sodium carbonate or ammonium carbonate [12].

Most researchers are now diverting their attention to the microemulsion route for the synthesis of different types of nanoparticles. Microemulsions are a thermodynamically stable, optically transparent, isotropic dispersion of two immiscible liquids, such as water and oil, stabilised by an interfacial film of a surfactant molecule [13]. The system is a single optical dispersion of thermodynamically stable liquids that typically consists of small particle droplets with diameters in the range of less than from $10 \mathrm{~nm}$ to $100 \mathrm{~nm}$ [14]. A microemulsion serves as a special microreactor that inhibits the growth of nanosized particles [15]. The advantage of this method is that it increases the homogeneity of the chemical decomposition at the nanolevel and allows the easy preparation of nanocrystals of comparatively equal sizes [16].

The research in this paper was focused on the synthesis of calcium carbonate nanocrystals from cockle shells by the microemulsion route using a HPH. The process is a top-down technique that occurs in a special homogenising valve at the heart of homogenising equipment. The fluid passes through a minute gap in the homogenising valve [17], which creates conditions of high turbulence and shear, combined with compression, acceleration, and a pressure drop. The impact causes disintegration of particles and dispersion throughout the sample [17]. After homogenisation, the particles are uniform in size, and their sizes depend on the number of cycles, the processing, and the operating pressure. The homogeniser is the most efficient device for the reduction of particle and droplet sizes.

To the best of our knowledge, no research related to the synthesis of calcium carbonate nanocrystals from biogenic origins or its reservoir using calcium carbonate as the main source of calcium and carbonate ions has been reported. Most research has focused on the use of chemical reactions, whereby the salts of calcium and carbonate ions act as the precursors for the synthesis of calcium carbonate nanocrystals.

\section{Experimental}

2.1. Synthesis of Calcium Carbonate Powder. Cockle shells were obtained from market. The calcium carbonate powders were prepared from the cockle shells according to the procedure described by Islam et al. [18]. Samples of the cockle shells were dried in an oven at $50^{\circ} \mathrm{C}$ for 7 days, and the shells were then crushed and blended into a fine powder, which was sieved through a $90-\mu \mathrm{m}$ laboratory stainless steel sieve (Endecott, London, England). The calcium carbonate powders were finally packed into a polyethylene plastic bag for further analyses.

2.2. Synthesis of Calcium Carbonate Nanocrystals. The synthesis of calcium carbonate nanocrystals was performed through oil-in-water $(\mathrm{O} / \mathrm{W})$ microemulsions using a $\mathrm{HPH}$. In this technique, the particles sizes are reduced after leaving the homogenising gap by cavitations, particle collisions, and shear forces $[19,20]$.

The calcium carbonate nanocrystals were prepared by the dissolution of $2 \mathrm{~g}$ of dry cockle shell powder in a formulated oil-in-water $(\mathrm{O} / \mathrm{W})$ microemulsion, which was moderately stirred by a magnetic stirrer for $5 \mathrm{~min}$ at $100 \mathrm{rpm}$ to form a calcium carbonate suspension. The formulated suspension was passed through the liquid inlet of a $\mathrm{HPH}$ for premilling at a moderate pressure of 300 and 500 bars for three cycles each. The premilled suspension was collected at the HPH outlet and was again passed through the HPH liquid inlet at a high pressure of 1500 bars for 25 homogenising cycles to obtain the desired product. The product of the crystal suspension was filtered and dried in an oven at $105^{\circ} \mathrm{C}$ for 24 hours.

\subsection{Characterisation of Calcium Carbonate Nanocrystals.} The following instruments were employed for the observation and characterisation of the calcium carbonate nanocrystals. The morphology and particle size of the nanocrystals were analysed using a transmission electron microscope (TEM, Hitachi H-7100) and a field-emission scanning electron microscope (FESEM, JOEL 7600F) operated at a voltage of 


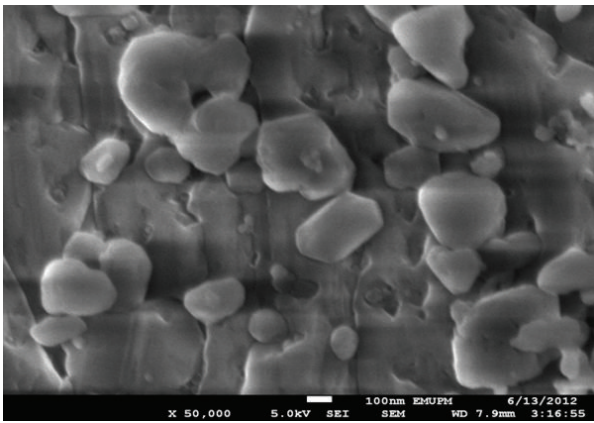

(a)

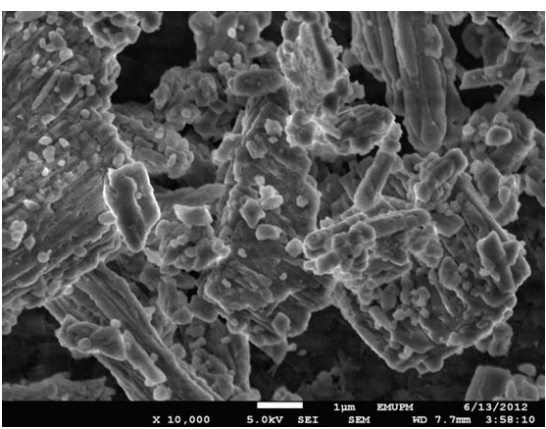

(b)

FIGURE 1: FESEM micrographs of (a) cockle shell calcium carbonate nanocrystals and (b) cockle shell powder.

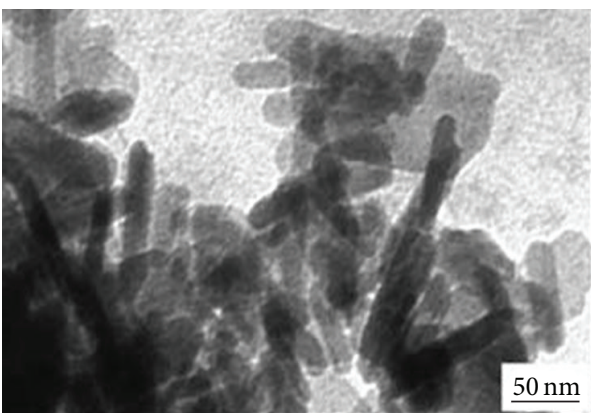

(a)

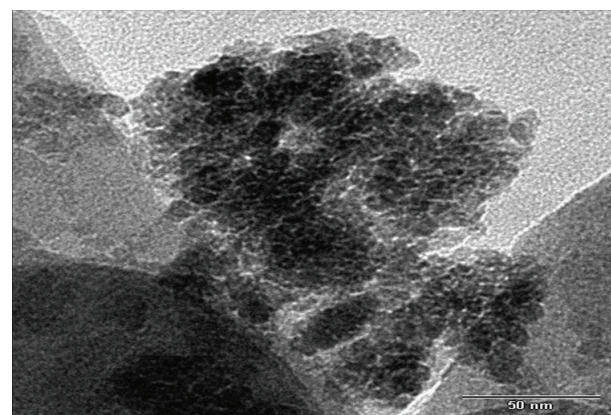

(b)

FIGURE 2: TEM images of (a) rod-shaped nanocrystals synthesised via microemulsion routes and (b) cockle shell powder without organic additive added.

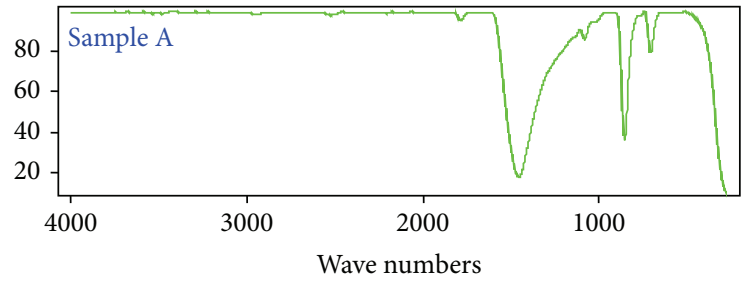

(a)



(b)

FIGURE 3: FTIR spectra of calcium carbonate nanocrystals (a) and cockle shell powder (b).

$5 \mathrm{kV}$ and equipped with an energy-dispersive X-ray spectroscopy (EDX) unit. The crystal powder was characterised by X-ray powder diffraction (XRD) using a Rigaku X-ray diffractometer equipped with a $\mathrm{Cu} \mathrm{K} \alpha(\lambda=0.15406 \mathrm{~nm})$ radiation source; samples were scanned at a rate of $40 / \mathrm{min}$.
Pellets of the calcium carbonate nanocrystals were calibrated in a weight proportion of $1 \mathrm{wt} \%$ in Ker, and analyses were performed with a Fourier-transform infrared spectrometer (FTIR, model 100, Perkin Elmer, 710 Bridgeport Avenue, Shelton, CT, USA) in the range of $400-4000 \mathrm{~cm}^{-1}$. Thermogravimetric analysis of the calcium carbonate nanocrystals was performed using a TG-DTA instrument (Netzsch STA449C) with an air flow of $100 \mathrm{~mL} / \mathrm{min}$ and a heating rate of $10 \mathrm{~K} / \mathrm{min}$ from room temperature to $1000^{\circ} \mathrm{C}$.

\section{Results and Discussion}

3.1. FESEM and TEM Characterisation of Calcium Carbonate Nanocrystals. The morphological characteristics of the calcium carbonate nanocrystals presented in Figures 1(a) and 1(b) are typical FESEM micrographs of the samples under study. The nanometre-sized and rod-shaped particles in Figure 1(a) were synthesised in the confined microemulsion system, whereas Figure 1(b) shows micrographs of a cockle shell powder without any organic additives. These results indicate a natural ability of the biological system to control specific size and morphology, which is very difficult to achieve using classical methods or colloid-chemistry routes [21]. A living organism has the ability to secrete macromolecules, such as in oyster shells, coral, mollusc shells and bivalve nacre. Living organisms achieve this natural 


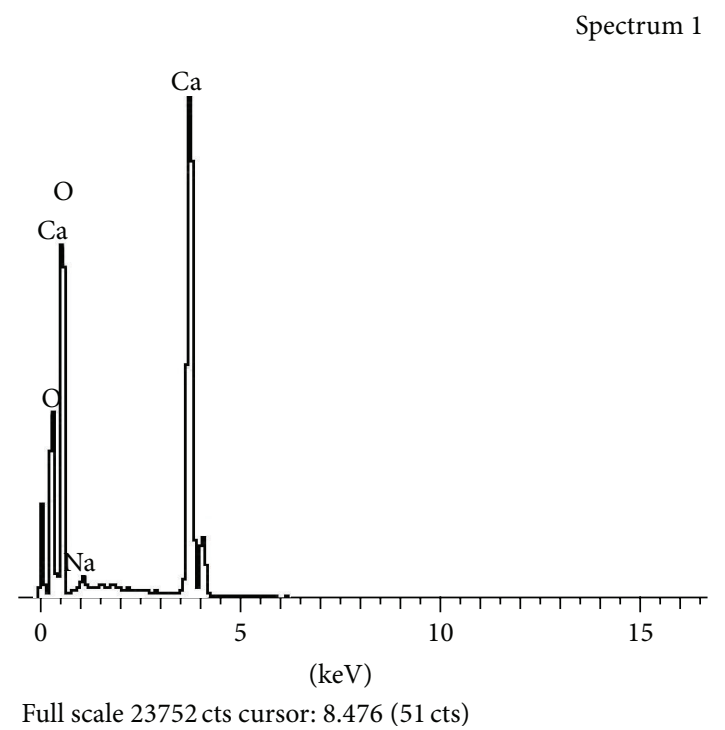

(a)

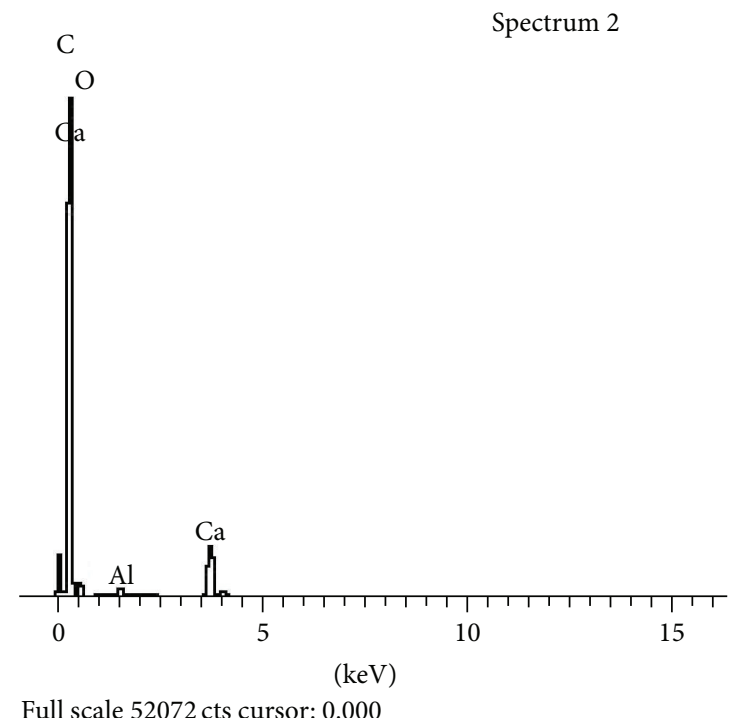

(b)

FIGURE 4: EDX spectral data for calcium carbonate nanocrystals and cockle shell powder.

phenomenon by utilising the secreted macromolecules (proteins, polysaccharides, and acidic macromolecules) as the nucleators (usually in the form of phospholipid membranes) to modulate the formation of a unique inorganic-organic material with a special morphology and function [21].

TEM was also used to study the calcium carbonate crystal particles. The images of the crystal presented in both Figures 2(a) and 2(b) reveal a rod shape of calcium carbonate aragonite polymorphs. The particles in Figure 2(a) are uniformly distributed at the nanometre scale and were formed in the microemulsion system; this system is considered an ideal medium for the preparation of inorganic nanoparticles [22]. The nanocrystal particles synthesised in the microemulsion system presented in Figure 2(a) differ in size, being approximately $50 \mathrm{~nm}$ with individual particles measuring $12-30 \mathrm{~nm}$; in addition, the shape of the particles is clear, and the difference in the particle size may result from the presence of Tween 80 used in the prepared microemulsion. In contrast, the particles shown in Figure 2(b) agglomerated, and the rod shape was not clear compared with the shape in Figure 2(a), which may be due to the differences in the preparation conditions and the additional surfactant (Tween 80) used. Surfactants, both ionic and nonionic, have been reported to strongly affect the size and morphology of calcium carbonate nanoparticles during synthesis [23]. However, nonionic surfactants have a weaker effect on the morphology than do ionic surfactants [23]. This result is most likely due to the weak interactions between a nonionic surfactant and $\mathrm{Ca}^{2+}$ and $\mathrm{CO}_{3}{ }^{2-}$ ions [24]; in addition, the microemulsion route, when used for the synthesis of nanoparticles, enables control of the size and morphology of the obtained materials [23].

\subsection{FTIR Spectra of Calcium Carbonate Nanocrystals. FTIR} spectra of the calcium carbonate nanocrystals are presented in Figures 3(a) and 3(b). FTIR spectroscopy is an important instrument used to identity different phases of organic and inorganic compounds and, specifically, calcium carbonate phases due to the differences in their carbonate ions, $\mathrm{CO}_{3}{ }^{2-}$. Carbonate ions and similar molecules have four normal modes of vibration peaks: $v_{1}$, symmetric stretching; $v_{2}$, outof-plane bending; $v_{3}$, doubly degenerate planar asymmetric stretching; and $v_{4}$, doubly degenerate planar bending [25]. The spectral data obtained for the samples reveal a broad absorption peak of $\mathrm{CO}_{3}{ }^{2-}$ at $\sim 1455 \mathrm{~cm}^{-1}, \sim 1082 \mathrm{~cm}^{-1}, \sim$ $1786 \mathrm{~cm}^{-1}, \sim 855 \mathrm{~cm}^{-1}$, and $\sim 709 \mathrm{~cm}^{-1}$, which have been reported to be the common characteristic features of the carbonate ions in calcium carbonate and are the fundamental modes of vibration for this molecule [26]. However, the observed bands at $\sim 1082 \mathrm{~cm}^{-1}$ and $\sim 855 \mathrm{~cm}^{-1}$ were carefully assigned as $v_{1}$ symmetric stretching and $v_{2}$ out-ofplane bending modes of $\mathrm{CO}_{3}{ }^{2-}$, respectively. The peak at $1082 \mathrm{~cm}^{-1}$ was only observed in the spectrum of aragonitephase calcium carbonate, whose $\mathrm{CO}_{3}{ }^{2-}$ ions are inactive in the infrared region. This observation was verified by other reports in the literature on characteristic infrared bands, which are experimentally not observed in the spectrum of calcite [26]. In contrast, the doubly degenerate peak that appears at $\sim 709 \mathrm{~cm}^{-1}$ can be attributed to the $v_{4}$ in-plane bending mode of $\mathrm{CO}_{3}{ }^{2-}$ ions, which indicates a structural change in the calcium ions from the symmetry of the calcite phase. This degeneracy can only be removed by splitting the band into two; thus, the band is attributed to the aragonite phase only, which has been confirmed in the literature [26]. This assertion was also supported by a very broad doubly degenerate band $v_{3}$ at $\sim 1452 \mathrm{~cm}^{-1}$, which confirms the structural changes in the symmetry of the $\mathrm{CO}_{3}{ }^{2-}$ molecular ions that correspond to the asymmetric stretching mode of $\mathrm{CO}_{3}{ }^{2-}$. A similar result was also reported by Cheng et al. [27]. The fundamental changes in the positions of the vibration mode of a molecule are caused by a modification of the electrostatic valence of the $\mathrm{Ca}-\mathrm{O}$ bond due to changes in 


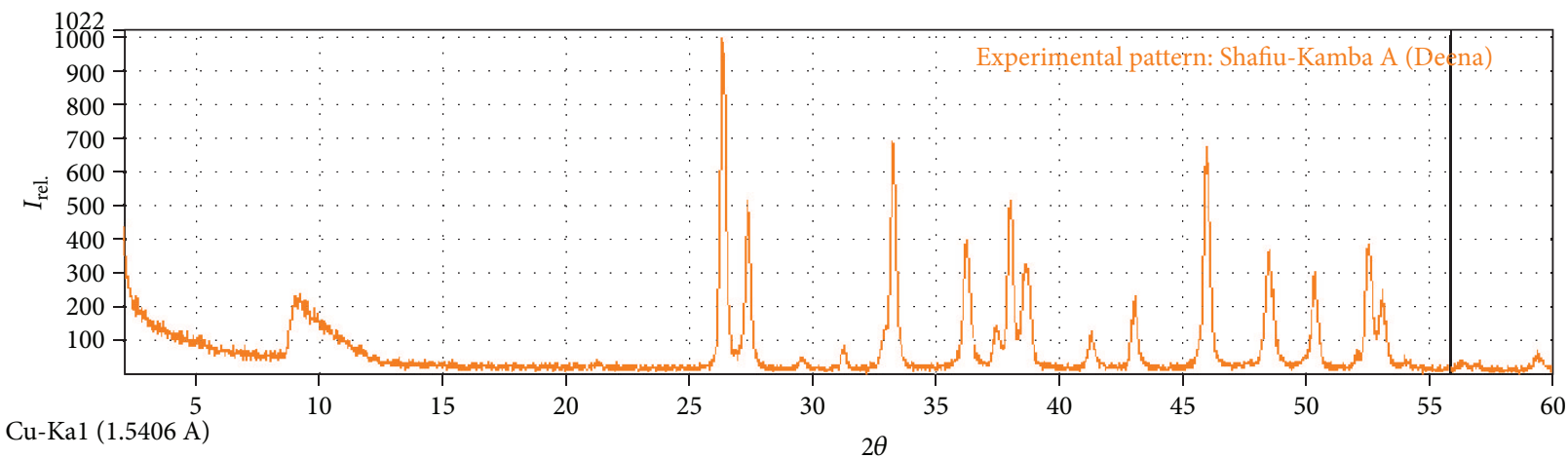

(a)

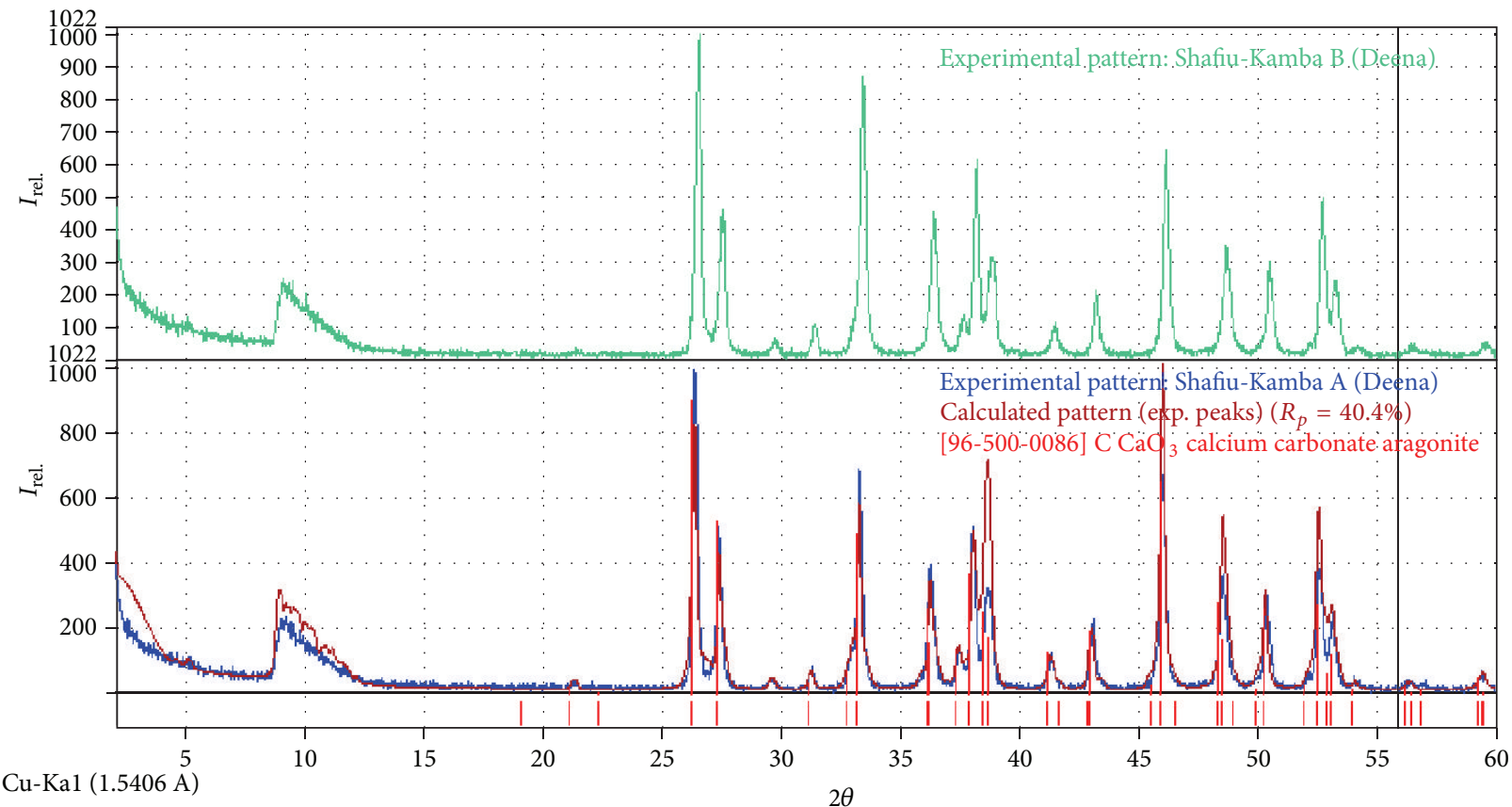

(b)

FIGURE 5: X-ray diffraction patterns of calcium carbonate nanocrystals (a) and cockle shell powder (b).

the coordination; the $\mathrm{Ca}-\mathrm{O}$ bond alteration occurs because the displacement of the carbonate vibration mode changes in the environment of oxygen atoms [26-28]. This evidence further demonstrates that the synthesis involves a single phase of calcium carbonate aragonite crystals. The observed IR frequencies at $\sim 1786 \mathrm{~cm}^{-1}$ and $\sim 252 \mathrm{~cm}^{-1}$ are due to the combination of the fundamental vibration frequencies of the carbonate molecular ions assigned between $\left(v_{1}\right.$ and $\left.v_{4}\right)$ and $\left(\mathrm{v}_{1}\right.$ and $\left.v_{3}\right)$, respectively, as reported in the literature [26-28].

Both the cockle shell powder and the synthesised calcium carbonate nanocrystals possess the same vibration frequencies as observed in the FTIR data obtained in Figure 3(a). The results demonstrate that the nonionic surfactant (Tween 80) used in the preparation of the microemulsion does not affect the vibration frequencies because no additional peaks were observed when the spectrum of the calcium carbonate nanocrystals was compared with that of the cockle shell powder in Figure 3(b). The cockle shell powder was prepared in distilled water only and without the use of additional organic additives or surfactants. This result may be due to the presence of a natural or organic matrix composed of an elastic biopolymer, such as the silk-like protein chitin; this organic matrix secreted by marine shell plays an important role in controlling the inorganic structure, morphology, size, and polymorphism [28, 29].

3.3. Elemental Compositions of Synthesised Nanocrystals and Cockle Shell Powder. The chemical compositions of the samples were analysed using EDX, which revealed the presence of individual elements in the samples. As indicated in Tables 1(a) and 1(b), the samples contained almost identical elements, with no significant differences observed between the elements detected in the two samples analysed. Both 


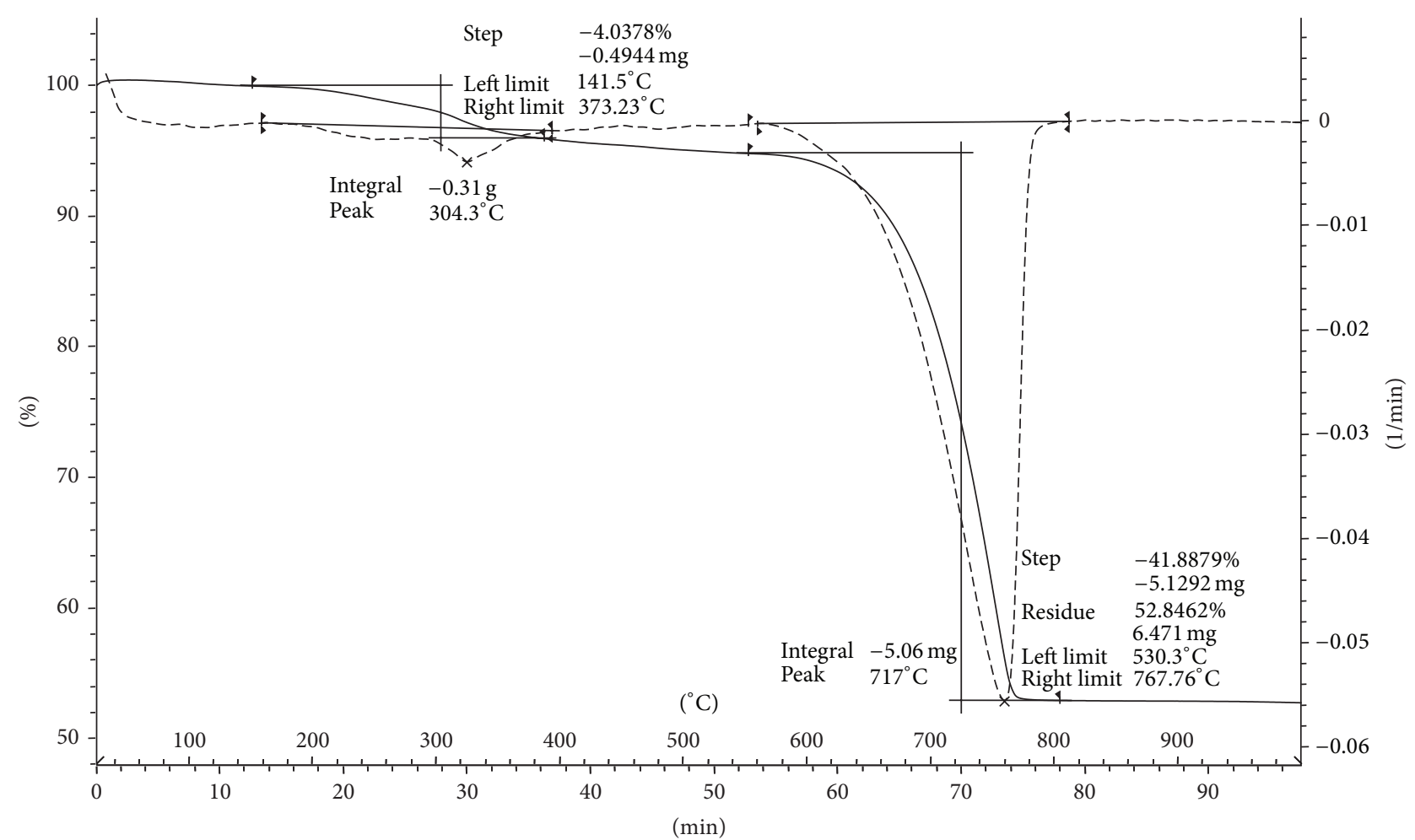

(a)

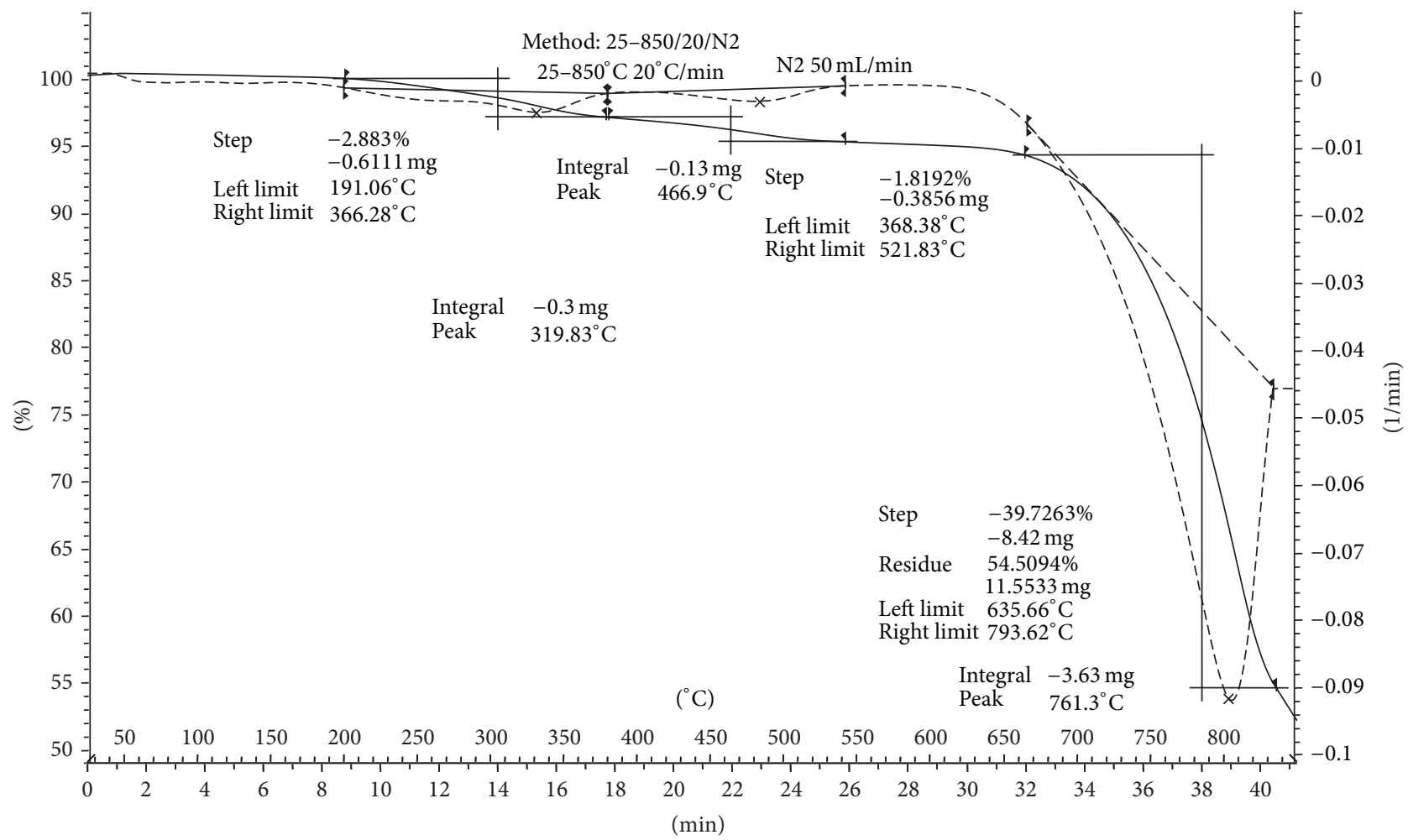

(b)

FIGURE 6: (a) Graphical representation of nanocrystal TGA results. (b) Graphical representation of cockle shells powder TGA data. 
TABLE 1: (a) Elemental compositions of calcium carbonate nanocrystals and (b) elemental compositions of cockle shell powder.

(a)

\begin{tabular}{|c|c|c|c|c|c|}
\hline Spectrum & Carbon & Oxygen & Sodium & Calcium & Total (\%) \\
\hline Spectrum 1 & 20.18 & 59.51 & 0.53 & 19.78 & 100.00 \\
\hline Spectrum 2 & 14.44 & 46.73 & 0.30 & 38.53 & 100.00 \\
\hline Spectrum 3 & 13.57 & 28.14 & 0.18 & 58.11 & 100.00 \\
\hline Mean & 16.06 & 44.79 & 0.34 & 38.81 & 100.00 \\
\hline Standard deviation & 3.59 & 15.78 & 0.17 & 19.17 & \\
\hline Max. & 20.18 & 59.51 & 0.53 & 58.11 & \\
\hline Min. & 12.65 & 28.14 & 0.18 & 19.78 & \\
\hline
\end{tabular}

(b)

\begin{tabular}{|c|c|c|c|c|c|c|}
\hline Spectrum & Carbon & Oxygen & Sodium & Calcium & Aluminium & Total (\%) \\
\hline Spectrum 1 & 22.18 & 50.51 & 0.53 & 27.60 & 0.17 & 100.00 \\
\hline Spectrum 2 & 12.44 & 46.32 & 0.30 & 30.53 & 0.41 & 100.00 \\
\hline Spectrum 3 & 13.57 & 37.14 & 0.18 & 58.11 & & 100.00 \\
\hline Mean & 16.06 & 44.79 & 0.34 & 38.81 & & 100.00 \\
\hline Standard deviation & 3.59 & 15.78 & 0.17 & 19.17 & & \\
\hline Max. & 19.82 & 69.52 & 0.36 & 58.11 & & \\
\hline Min. & 13.57 & 26.42 & 0.16 & 23.87 & & \\
\hline
\end{tabular}

samples contained negligible traces of elemental sodium, and a minute percentage of aluminium was recorded only in the cockle shell powder (Figure 4(b)). This analysis proves that the composition of the calcium carbonate in the cockle shell powder is not $100 \%$ pure due to the presence of other elements such as aluminium and sodium.

3.4. X-Ray Diffraction Pattern of Calcium Carbonate Nanocrystals. X-ray diffraction is a sensitive instrument used for the identification of crystalline phases of inorganic compounds. The data obtained from the X-ray diffraction patterns in Figures 5(a) and 5(b) demonstrate the crystalline nature and phase composition of both samples under analysis. The X-ray diffraction pattern of the synthesised calcium carbonate nanocrystals and cockle shell powder in Figures 3(a) and of 3(b) exhibits characteristics peaks of aragonite at $2 \theta$ values of $26.34^{\circ}, 33.24^{\circ}, 45.98^{\circ}$ and $26.31^{\circ}$, $33.24^{\circ}, 45.98^{\circ}$, and respectively, which correlate with (hkl) indices of (111), (012), (221), and (021), (0.12), and (221), respectively. These are the strongest peaks observed in the X-ray diffraction patterns of the analysed samples. However, peaks are also observed at $26.71^{\circ}, 26.87^{\circ}, 27.02^{\circ}$, $27.38^{\circ}, 27.57^{\circ}, 27.72^{\circ}, 41.28^{\circ}, 45.62^{\circ}, 46.54^{\circ}, 48.84^{\circ}$, and $52.53^{\circ}$. These values also correspond with calcium carbonate aragonite polymorphs reported in the PDF-4+ data bank of the International Centre for Diffraction Data [30]. All the reflections can be attributed to the pure aragonite phase of calcium carbonate, which validates the FTIR results of the aragonite polymorph of calcium carbonate.

3.5. Thermal Decomposition of Calcium Carbonate Nanocrystals. Thermogravimetric analyses of the cockle shell powder and the nanocrystals synthesised from the powder were performed using the shrinking core model (SCM), whereby the reaction usually begins from the outer layer of the particles and moves toward the solid, which yields an ash solid as the converted material [5]. Therefore, Figures 6(a) and 6(b) illustrate the weight losses of the samples analysed during the process. Both samples were stable until $300^{\circ} \mathrm{C}$ and then decomposed in two steps. The first step was the initial process, which started with a very small weight loss of $4.0 \%$ due to the moisture content in the samples [31]; a similar result has been reported by Yu et al. [32] for bulk or microcalcium carbonate, and this value would also be the loss for nanoparticles of the same material, as reported as by Mohamed et al. [5]. Endothermic behaviour was also observed in the temperature range from 304 to $373^{\circ} \mathrm{C}$, which may be due to the removal of water molecules from the carbonate lattice and the phase transformation of aragonite to calcite due to its unstable nature, as described previously. The phase transition of aragonite to calcite in coral and other marine shells occurs at a lower temperature than that of the phase transition in aragonite of mineral origin [26]. Second, a rapid weight loss of $41.88 \%$ and endothermic behaviour from 600 to $800^{\circ} \mathrm{C}$ were observed in both samples; in this temperature range, volatile minerals in the sample began to decompose, thereby releasing $\mathrm{CO}_{2}$. For the cockle shell powder, the rate of decomposition was slower compared with that of the nanocrystals, as shown in Figure 6(a); this result has been reported in the literature, whereby particles of smaller size decompose faster than larger particles [5] because smaller-sized particles have a greater surface area than larger particles. However, both samples remained unchanged when the temperature reached $900^{\circ} \mathrm{C}$. This result indicates the total decomposition of calcium carbonate to $\mathrm{CaO}$ and signifies the release of $\mathrm{CO}_{2}$ from calcium carbonate, leaving only the product, that is, "ash" [5]. This assumption 
derived from the TGA analysis is also supported by the XRD data shown in Figure 5.

\section{Conclusions}

Cockle shells consist of a higher percentage of calcium carbonate aragonite polymorphs, as described in the introduction of this paper. On the basis of the analysis of calcium carbonate nanocrystals from the cockle shell powder and that of the powder itself, the shells are composed of the aragonite form of calcium carbonate, which is less stable and denser than calcite. These properties make it a potential biomaterial for medical applications. The thermogravimetric analyses of the two samples revealed the solid-state phase transformation of aragonite to calcite. The transformation of aragonite began at approximately at $300-373^{\circ} \mathrm{C}$ and at $600-$ $700^{\circ} \mathrm{C}$; the complete removal of volatile substances occurred, and the phase transformation of aragonite to calcite was completed with a loss of $41 \%$ of the initial weight of the sample. These results also demonstrate that smaller particles decompose faster than larger particles within a short time at low temperatures.

The methods adopted and the nonionic surfactant used in the synthesis of aragonite nanocrystals are environmentally friendly and could be scaled up for industrial production, thereby permitting a greener synthesis from naturally available materials and utilising the waste shells that are a byproduct of the seafood industry. This method thus offers a great opportunity for exploitation in numerous industrial applications.

\section{Conflict of Interests}

The authors would like to confirm that there is no conflicts of interests associated with this paper submitted for publication, and there has been no significant financial support for this work that could have affected its outcome. The authors confirm that the paper has been read and approved by all named authors and that there are no other persons who satisfy the criteria for authorship but who are not listed. The authors further confirm that the order of authors listed in the paper has been approved by all of the authors. The authors confirm that they have given due consideration to the protection of intellectual property associated with this work and that there are no impediments to publication, including the timing of publication, with respect to intellectual property. In so doing, The authors confirm that they have followed the regulations of their institutions concerning intellectual property.

\section{References}

[1] A. Xu, Y. Ma, and H. Colfen, "Biomimetic mineralization," Journal of Material Chemistry, vol. 17, pp. 415-449, 2006.

[2] Y. Fukui and K. Fujimoto, "Bioinspired nanoreactor based on miniemulsion system to create organic-inorganic hybrid nanoparticle and nanofilm," Journal of Material Chemistry, vol. 22, no. 8, pp. 3493-3499, 2012.

[3] Q. L. Feng, G. Pu, Y. Pei, F. Z. Cui, H. D. Li, and T. N. Kim, "Polymorph and morphology of calcium carbonate crystals induced by proteins extracted from mollusk shell," Journal of Crystal Growth, vol. 216, no. 1, pp. 459-465, 2000.

[4] R. Velázquez-Castillo, V. Reyes-Gasga, D. I. García-Gutierrez, and M. Jose-Yacaman, "Nanoscale characterization of nautilus shell structure: an example of natural self-assembly," Journal of Materials Research, vol. 21, no. 6, pp. 1484-1489, 2006.

[5] M. Mohamed, S. Yusup, and S. Maitra, "Decomposition study of calcium carbonate in cockle shells," Journal of Engineering Science and Technology, vol. 7, no. 1, pp. 1-10, 2012.

[6] A. J. Awang-Hazmi, A. B. Z. Zuki, M. M. Nordin, A. Jalila, and Y. Norimah, "Mineral composition of the cockle (Anadara Granosa) shells of west coast of peninsular Malaysia and its potential as biomaterial for use in bone repair," Journal of Animal and Veterinary Advances, vol. 6, no. 5, pp. 591-594, 2007.

[7] Y. Guowei., L. Wang, and H. Jianhua, "The crystallization behavior of calcium carbonate in ethanol/water solution containing mixed nonionic/anionic surfactants," Powder Technology, vol. 192, no. 1, pp. 58-64, 2009.

[8] R. Gupter, Synthesis of Precipitated Calcium Carbonate Nanoparticles Using Modified Emulsion Membranes [M.S. thesis], Georgia Institute of Technology, Atlanta, Ga, USA, 2004.

[9] G. X. Wu, J. Ding, and J. M. Xue, "Synthesis of calcium carbonate capsules in water-in-oil-in-water double emulsions," Journal of Materials Research, vol. 23, no. 1, pp. 140-149, 2008.

[10] T. A. Hassan, V. K. Rangari, V. Fallon, Y. Farooq, and S. Jeelani, "Mechanochemical and sonochemical synthesis of bio-based nanoparticles," in Proceedings of the Nanotechnology Conference, pp. 278-281, June 2010.

[11] A. Georgieva, B. Georgieva, Z. Bogdanov, and D. K. Stefanov, "Microemulsion water-in-oil (W/O) - microreactor for synthesis of ultrafine carbonate nanostructures," University of Ruse Union of Scientists-Ruse, vol. 50, no. 9, pp. 34-38, 2011.

[12] R. Babou-Kammoe, S. Hamoudi, F. Larachi, and K. Belkacemi, "Synthesis of calcium carbonate nanoparticles by controlled precipation of saturated carbonated and calcium Nitrate aqueous solution," The Canadian Journal of Chemical Engineering, vol. 90, pp. 26-33, 2012.

[13] Y. H. Cho, S. Kim, E. K. Bae, C. K. Mok, and J. Park, "Formulation of a cosurfactant-free $\mathrm{O} / \mathrm{W}$ microemulsion using nonionic surfactant mixtures," Journal of Food Science, vol. 73, no. 3, pp. E115-E121, 2008.

[14] S. Talegaonkar, A. Azeem, F. J. Ahmad, R. K. Khar, S. A. Pathan, and Z. I. Khan, "Microemulsions: a novel approach to enhanced drug delivery," Recent Patents on Drug Delivery and Formulation, vol. 2, no. 3, pp. 238-257, 2008.

[15] K. C. Song and J. H. Kim, "Synthesis of high surface area tin oxide powders via water-in-oil microemulsions," Powder Technology, vol. 107, no. 3, pp. 268-272, 2000.

[16] C. Karagiozov and D. Momchilova, "Synthesis of nano-sized particles from metal carbonates by the method of reversed mycelles," Chemical Engineering and Processing, vol. 44, no. 1, pp. 115-119, 2005.

[17] GEA_Niro_Soavi, "Laboratory Manual for Higher pressure Homogenizer," 2011, http://www.nirosoavi.com/index.asp.

[18] N. Islam, Z. B. A. Bakar, M. M. Noordin, M. Z. B. Hussain, N. S. B. A. Rahman, and E. Ali, "Characterisation of calcium carbonate and its polymorphs from cockle shells (Anadara granosa)," Powder Technology, vol. 213, no. 1-3, pp. 188-191, 2011.

[19] K. Mitri, R. Shegokar, S. Gohla, C. Anselmi, and R. H. Müller, "Lutein nanocrystal as antioxidant formulation for oral and 
dermal delivery," International Journal of Pharmaceutics, vol. 420, pp. 141-146, 2011.

[20] R. Shegokar and R. H. Müller, "Nanocrystals: industrially feasible multifunctional formulation technology for poorly soluble actives," International Journal of Pharmaceutics, vol. 399, no. 1-2, pp. 129-139, 2010.

[21] B. Cheng, M. Lei, J. Yu, and X. Zhao, "Preparation of monodispersed cubic calcium carbonate particles via precipitation reaction," Materials Letters, vol. 58, no. 10, pp. 1565-1570, 2004.

[22] Y. Dong, Y. Chu, L. Dong, and Z. Yu-jiang, "Controllable synthesis of $\mathrm{CaCO}_{3}$ micro/nanocrystals with different morphologies in microemulsion," Chemical Journal of Chinese Universities, vol. 26, no. 5, pp. 678-682, 2010.

[23] A. Szcześ, "Influence of the surfactant nature on the calcium carbonate synthesis in water-in-oil emulsion," Journal of Crystal Growth, vol. 311, no. 4, pp. 1129-1135, 2009.

[24] Y. Tang, B. Du, L. Li, J. Yang, and Y. Zhang, "Effects of Tx$100-S D S$ on crystal growth of calcium carbonate in reverse microemulsion solution," Chinese Science Bulletin, vol. 52, no. 1, pp. 78-83, 2007.

[25] Y. Wang, Y. X. Moo, C. Chen, P. Gunawan, and R. Xu, "Fast precipitation of uniform $\mathrm{CaCO}_{3}$ nanospheres and their transformation to hollow hydroxyapatite nanospheres," Journal of Colloid and Interface Science, vol. 352, no. 2, pp. 393-400, 2010.

[26] C. Linga Raju, K. V. Narasimhulu, N. O. Gopal, J. L. Rao, and B. C. V. Reddy, "Electron paramagnetic resonance, optical and infrared spectral studies on the marine mussel Arca burnesi shells," Journal of Molecular Structure, vol. 608, no. 2-3, pp. 201211, 2002.

[27] B. Cheng, W. Cai, and J. Yu, "DNA-mediated morphosynthesis of calcium carbonate particles," Journal of Colloid and Interface Science, vol. 352, no. 1, pp. 43-49, 2010.

[28] V. Vongsavat, P. Winotai, and S. Meejoo, "Phase transitions of natural corals monitored by ESR spectroscopy," Nuclear Instruments and Methods in Physics Research B, vol. 243, no. 1, pp. 167-173, 2006.

[29] Y. Hu, Y. Ma, Y. Zhou, F. Nie, X. Duan, and C. Pei, "Hen eggwhite-mediated stack crystallization of calcium carbonate," Journal of Crystal Growth, vol. 312, no. 6, pp. 831-836, 2010.

[30] C. A. Korash, "Mechanical properties of a Nanostructure Poly (KAMPS)/Aragonite composite," in Mechanic of Biological System and Materials. Volume 2, Conference proceedings of the society for expiremental mechanic series, pp. 131-136, 2011.

[31] Powder Diffraction File-4 Releas, International Centre for Diffraction Data (ICDD), Newton square, Pa, USA, 2012.

[32] J. Yu, H. Guo, S. A. Davis, and S. Mann, "Fabrication of hollow inorganic microspheres by chemically induced selftransformation," Advanced Functional Materials, vol. 16, no. 15, pp. 2035-2041, 2006. 

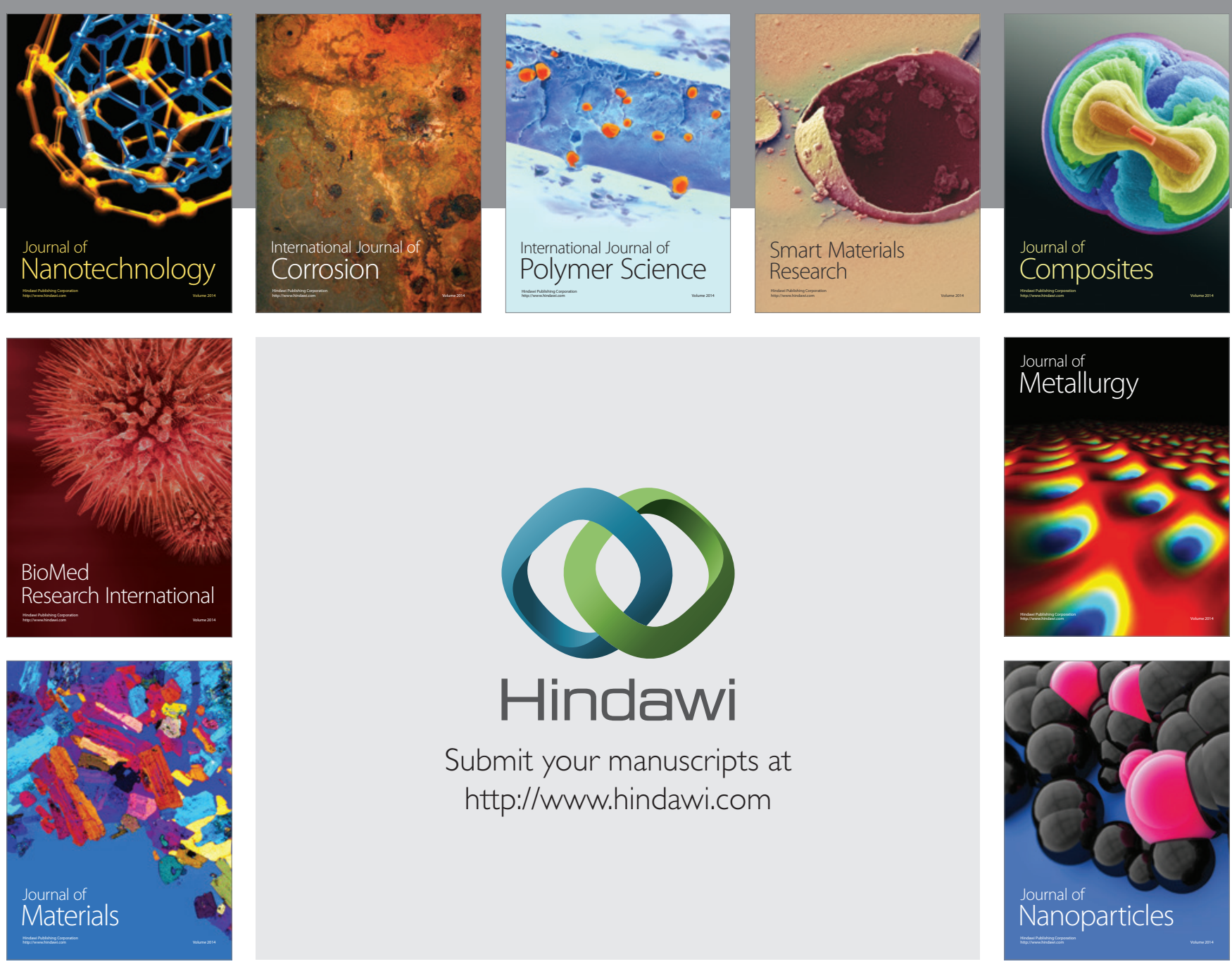

Submit your manuscripts at http://www.hindawi.com
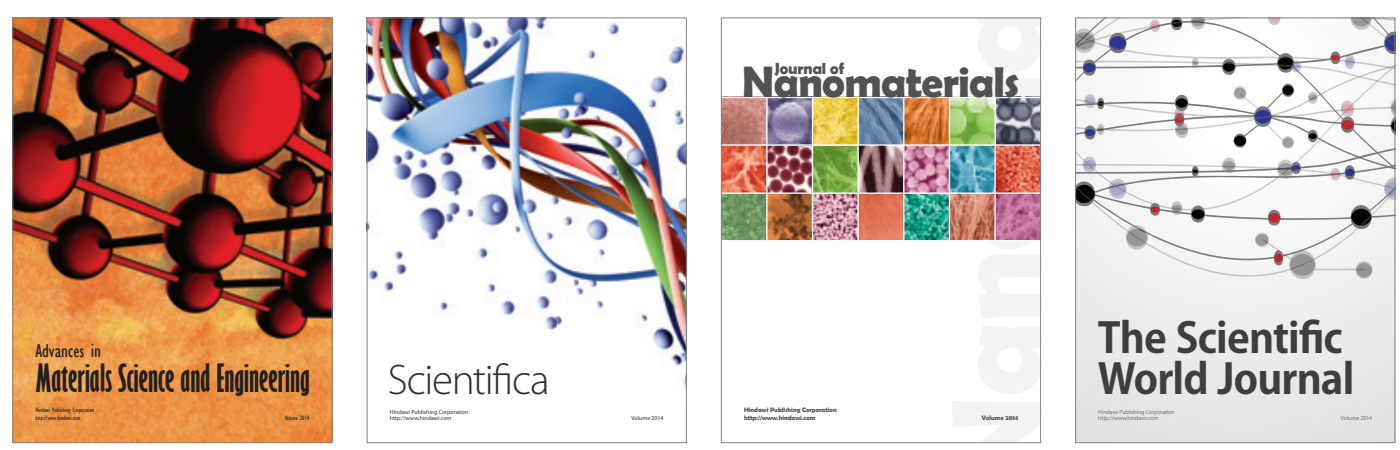

\section{The Scientific World Journal}
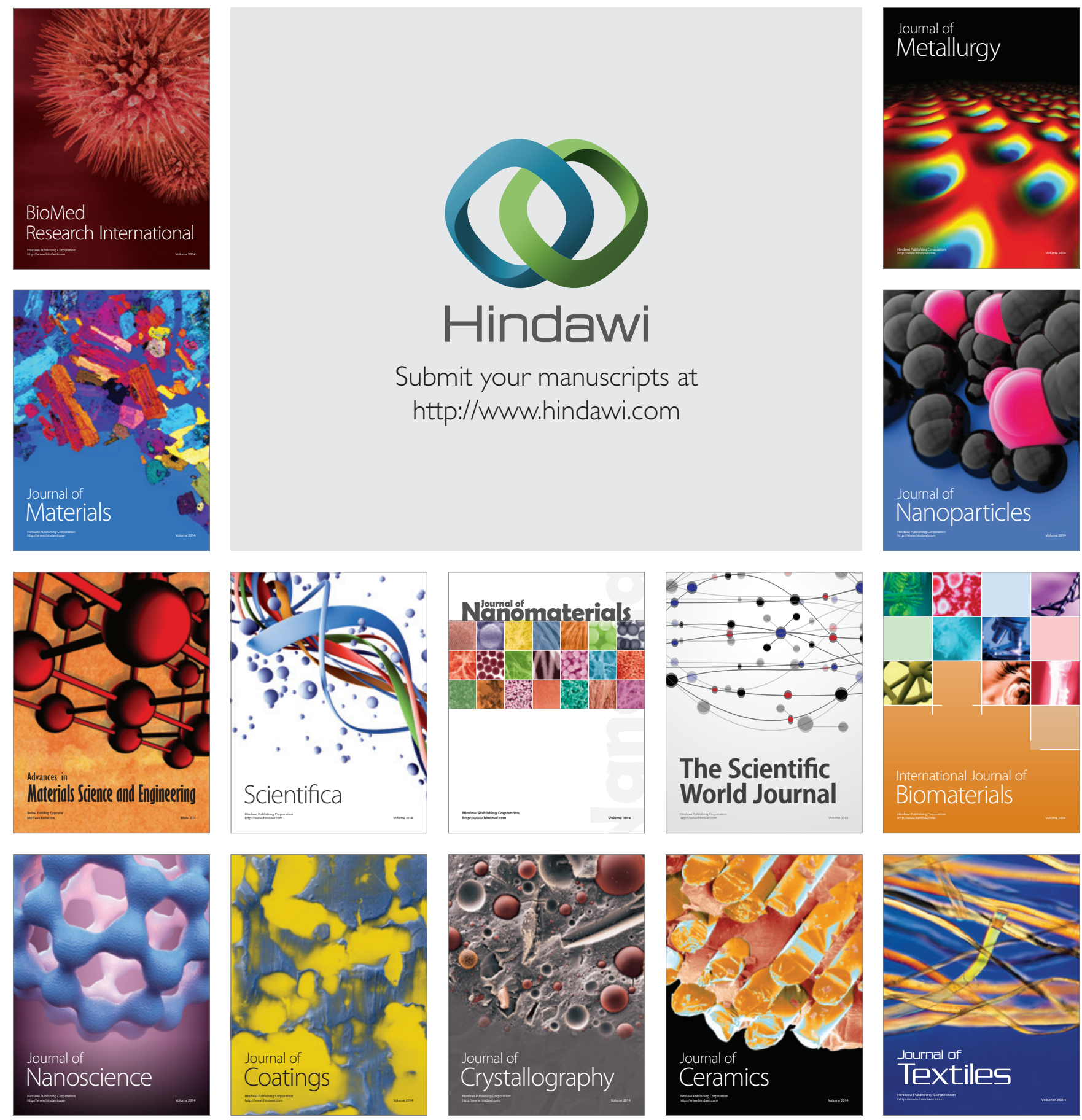